\section{To create generalists, teach students how to learn by themselves}

Sir — In his Millennium Essay, Frederick Seitz ${ }^{1}$ makes a compelling case for the importance of generalists - individuals with broad vision - in all cultural fields, and he laments that their ranks are thinning. I subscribe entirely to Seitz's assessment, yet I disagree with his analysis of what causes this trend and with his suggested remedy: reforming elementary and secondary education.

It has become almost a cliché in the United States and Europe to blame schools for society's increasing cultural ignorance. Yet many schools have struggled for years to maintain a diverse curriculum, despite budgetary constraints and conflicting societal demands.

Even so, a school's ability to affect students' cultural breadth is very limited. Children spend most of their time with family and friends, not at school. Parents need to provide daily evidence that they value diverse cultural pursuits: if they let their children devote an inordinate amount of time to a narrow range of activities, schools cannot be expected to produce people with differing values.

Provided parents have planted the seed of cultural and intellectual curiosity in their children, there is little that colleges and universities can do to kill it, but they can nurture it to a lesser or greater extent. Seitz considers that university teaching staff have virtually no room to manoeuvre against the strong internal and external forces that promote specialization. Chief among these, according to Seitz, are "conditions of intense competition", which leave little time for scholars to cultivate new, diverse interests.

Examples abound, however, of scholars such as Einstein, Jaynes and Mandelbrot who gained prominence and significant competitive advantages in their field precisely because they were able to borrow concepts, tools and methods from disciplines far from their own.

The growing complexity of most fields of research, which Seitz also mentions as an incentive to specialize, has to be put in historical perspective. A century and a half ago, scholars in North America and Europe were expected to be well versed in all branches of knowledge, and to remain so during their whole lives.

Admittedly, most fields of research have become much more complex since then, but the level of specialization of most scholars has increased incommensurably. I believe that colleges and universities are responsible for this, not because of pressures on them but because of their approach to learning.

By the second half of the nineteenth century, undergraduate education was in many respects similar to what we have now and, except in a handful of English institutions such as Oxford and Cambridge universities, did little to equip students with the skills necessary to keep learning new disciplines and updating their knowledge. On the other hand, an old tradition of "selfstudy" in society at large provided them with these skills ${ }^{2}$. Early graduate programmes in Germany and, for a time, at Johns Hopkins ${ }^{3}$ emulated this in their system of "self education under guidance".

In the early part of the twentieth century, however, universities eradicated selfdirected learning from the educational landscape. They successfully promoted the idea that quality learning can occur only in the physical or, more recently, 'virtual' presence of a teacher. With rare exceptions $s^{4,5}$, colleges and universities nowadays do not prepare students to keep learning on their own after they leave college. As a result, many graduates (including many who become academics) find that their lack of skills renders learning inefficient and slow. The best they can do is to deviate as little as possible from the narrow trajectory on which they were placed during their initial training, or retraining in the private sector.

To alleviate the resulting cultural and intellectual atrophy, colleges and universities must rethink their attitude towards self-directed learning, and implement imaginative ways to foster it effectively. Philippe Baveye

Laboratory of Environmental Geophysics, Bradfield Hall, Cornell University, Ithaca, New York 14853, USA and School of Education, University of Paris X, 92001 Nanterre, France

1. Seitz, F. Nature 403, 483 (2000).

2. Kett, J. F. The Pursuit of Knowledge under Difficulties (Stanford Univ. Press, Stanford, 1994).

3. Ludmerer, K. M. Learning to Heal: The Development of American Medical Education (Johns Hopkins Univ. Press, Baltimore, 1985).

4. Baveye, P. in Current Developments in Self-directed Learning (eds H. B. Long et al.) 157-175 (College of Education, University of Oklahoma, Norman, 1996)

5. Candy, P. C., Crebert, G. \& O'Leary, J. Developing Lifelong Learners through Undergraduate Education (Australian Government Publishing Service, Canberra, 1994).

\section{We have touched the dust from dying stars}

Sir-Adam Burrows's superbly eloquent review article ${ }^{1}$ about supernova explosions omits one aspect of supernovae that is so stunning that it adds to the context of his essay. Namely, that the human race holds solid samples of supernovae in its hands, and studies those samples in terrestrial laboratories.
Mostly micrometre-sized balls of $\mathrm{SiC}$ and graphite, they contained at the time of their condensation such staggering concentrations of ${ }^{41} \mathrm{Ca},{ }^{44} \mathrm{Ti}$ and ${ }^{26} \mathrm{Al}$ that the huge daughter abundances unequivocally declare these grains to be condensates within the interiors of their expanding supernova hosts ${ }^{2}$. Very non-solar isotopic ratios of the stable elements $\mathrm{C}, \mathrm{Si}$ and $\mathrm{N}$ within them confirm this diagnosis. These solid grains are local pieces of diverse supernova interiors, before any mixing with circumstellar matter. As part of the interstellar dust, they found their way into meteorites when those bodies grew at the birth of the Sun. They illuminate unforeseen details of supernova nucleosynthesis and supernova hydrodynamics.

Donald D. Clayton

Department of Physics and Astronomy, Clemson University, Clemson SC 29634-0978, USA

1. Burrows, A. Nature 403, 727 (2000).

2. Clayton, D. D., Amari, S. \& Zinner, E. Astrophys. Space Sci. 251, 355 (1997).

\section{Confusion over cash for Indian biotech centre...}

Sir-Despite your News report "Funding crisis for Indian biotech centre" (Nature 403,$694 ; 2000$ ), we have not halted recruitment at the Indian branch of the International Centre for Genetic Engineering and Biotechnology (ICGEB). Several scientists have recently joined the centre and none has left. Our financial support from the Indian government and from Italy is continuing without reduction. Furthermore, the Indian government has recently provided additional support for several new programmes at our centre, particularly the malaria vaccine project. V.S. Chauhan

Director, ICGEB, PO Box 10504, Aruna Asaf Ali Marg, New Delhi 110 067, India

\section{though funding states have promised to pay up}

Sir - It is not true to say that the member states are refusing to pay their contribution to the ICGEB; on the contrary, at the latest meeting of our board of governors, all the delegations expressed their firm intention to fulfil their statutory financial obligation according to the agreed scale of contributions.

Furthermore, the New Delhi component of ICGEB is not funded by "grants" from Trieste: ICGEB is a single entity and its two components in Trieste and New Delhi are both funded from the ICGEB regular budget, an essential 
element of which comes from the Indian government. Finally, there is no restriction in the centre's budget: the two host governments (Italy and India) both intend to increase their contributions, and we are confident that the other member states will fulfil their obligations. If any minor financial restrictions are made, they would affect equally both the Italian and the Indian components.

Arturo Falaschi

Director, ICGEB, Padriciano 99,

34012 Trieste, Italy

\section{K. S. Jayaraman replies - I stand by my} story. When I spoke to him, Dr Chauhan confirmed my information that the last scientist to join the centre at senior level did so four years previously. The cuts in the centre's grants ( 10 per cent now and a total of 25 per cent by 2001) were also confirmed by Dr Chauhan during our conversation.

\section{The lasting value of Mitchell's mechanisms}

Sir-As Leslie Orgel ${ }^{1}$ and Bo Malmström ${ }^{2}$ have valuably reminded us, Peter Mitchell opened up new vistas in bioenergetics when he formulated his chemiosmotic theory. The theory itself was a special case of his more general view on vectorial metabolism, a concept which little influenced his contemporaries although it formed a critically important part of his own intellectual odyssey. The chemiosmotic theory, initially formulated without experimental support, in time provided a framework for the development of our modern understanding of bioenergetics.

Was Mitchell never right on the mechanistic level? He certainly came up with mechanisms in large numbers. When I visited him late in his life he showed me several of them, covering various questions. There were yet more piled up on the window ledge. His private papers include many more. It is true that most of these ingenious schemes led nowhere, including those covering the involvement of protons in the ATPase and in the cytochrome oxidase, as well as some curious schemes for metabolite and ion transport. Indeed, Mitchell was allergic to systems that depended on processes which at the time could not be defined precisely at the molecular level, such as the conformational processes that he regarded as 'black box' biochemistry because they relied on an unspecified and unknown mechanism.

However, one mechanism that came to him in the middle of a sleepless night has been an outstanding success. This is the Q cycle ${ }^{3}$ for the transport of protons across the inner mitochondrial membrane by the ubiquinone-cytochrome $c$ reductase complex. This surely gave major support to the chemiosmotic theory in a period when the validity of the theory was itself still under debate. Perhaps this one achievement, together with the chemiosmotic theory with all its implications, justifies so many apparently fruitless mechanisms.

John Prebble

School of Biological Sciences, Royal Holloway College, University of London, Egham Hill, Egham, Surrey TW20 OEX, UK

1. Orgel, L. Nature 402, 17 (1999).

2. Malmström, B. Nature 403, 356 (2000).

3. Mitchell, P. FEBS Lett. 56, 1-6 (1975).

\section{People must be judged in the context of their time}

Sir-Alison Abbott reports on the Max Planck Society's recent efforts to shed light on its history, as the Kaiser Wilhelm Society, during the Third Reich (Nature $403,474-475 ; 2000$ ). This attempt is all the more important as investigations in the past encountered some reserve, whereas new information is now available and a new generation of science historians is examining the past, supposedly without any preconceptions.

However, the example of Hans Stubbe, first director of the Kaiser Wilhelm Institute (KWI) for Cultivated Plant Research (established near Vienna in 1943 and built up after the war at Gatersleben in East Germany) raises doubts as to the investigators' impartiality. Portraying Stubbe as "an opportunist, ruthlessly following any path that would help him to advance his research and career" and saying that he "collaborated with the SS to plunder valuable Russian collections of wild and cultivated plants" is unjustified.

The Russians themselves judged differently, since Stubbe received their backing to build the institute at Gatersleben and was highly honoured by the Soviet Union in spite of being an outspoken opponent of Lysenkoism - an intervention that saved East German genetics from the damage inflicted in other Eastern bloc countries. Contemporaries know that Stubbe protected several colleagues who faced difficulties with the Nazi or the East German system and enabled them to continue their work. He had himself been expelled from the KWI in 1936 for political reasons.

We can only beg those historians who never experienced a totalitarian regime to avoid hasty moral judgements and not to base their conclusions on what Jens Jessen has described in the German newspaper Die Zeit as "moral maximalism", without any feeling for the unavoidable entanglement in guilt and the tragedy always involved in making any significant decision within a totalitarian system. We need a careful documentation of all the historical facts, but we can also ask that people be judged within the historical context in which they lived and worked. Ulrich Wobus, Ingo Schubert

Institute of Plant Genetics and Crop Plant Research, D-06466 Gatersleben, Germany

Heim replies - Wobus and Schubert say it is "unfair" and "unjustified" to claim that Hans Stubbe collaborated with the SS to plunder valuable Russian collections of wild and cultivated plants. But there is extensive historical evidence testifying to precisely these facts.

The extended documentary trail left by Stubbe in various German archives contains a great deal of evidence about his close connections to the SS, especially his collaboration on a broad level with the SSFoundation Ahnenerbe, or 'Ancestral Heritage' - the Nazi research organization. A 1944 document bearing Stubbe's signature shows that members of his institute were carrying out "extensive research in the field of biological warfare". Documents of this time make it clear that he supported the 'rescuing' of valuable plant materials from Russian soil.

Alison Abbott pointed out correctly that Stubbe was not an "out-and-out Nazi"; he has to be seen in his ambivalence. He came under suspicion by the Gestapo, for example, while maintaining good relations with the SS. There is no evidence of antisemitism in Stubbe's Nazi-era correspondence, although after the war he helped at least one former SS officer from Auschwitz get his name cleared.

It is this ambiguity which makes him interesting for studying the role of scientists during the Nazi era, because his combination of attitudes is probably more typical than the black-and-white cases.

Stubbe's merits as a geneticist in postwar East Germany and his recognition and appreciation by postwar Soviet authorities do not prove anything about his role during the Nazi period. Wobus and Schubert's reprimand of "historians who never experienced a totalitarian regime" recalls the outmoded idea that one cannot write good history without having lived through the same conditions as the people being described.

The more important lesson, I would argue, is that scientists concerned about history should be as willing to examine the bad as the good. Stubbe was indeed a complex figure who lived in a difficult time, but we do no service to the past or the present of science by ignoring its seamier sides.

\section{Susanne Heim}

Max Planck Institute for the History of Science, Wilhelmstrasse 44, 10117 Berlin, Germany 